\title{
PLUS SIZE EXISTE? UMA ANÁLISE DA EXPERIÊNCIA DE CONSUMO DE INDIVÍDUOS DESCONSIDERADOS PELO MERCADO DE MODA
}

\author{
DOES PLUS SIZE EXISTS? AN ANALYSIS \\ OF THE COMSUPTION EXPERIENCE OF \\ INDIVIDUALS DISREGARDED BY THE \\ FASHION MARKET
}

\section{RESUMO}

Considerando o aumento da população brasileira acima do peso em contraste com um mercado de moda plus size ainda em desenvolvimento, este artigo investiga o conceito de experiência de consumo de roupas sob a ótica de consumidores plus size. Trata-se de uma pesquisa qualitativa, realizada por meio de 10 entrevistas em profundidade com consumidores desse segmento. Os resultados obtidos mediante uma análise de conteúdo identificaram três categorias temáticas: Experiência com o Produto, Experiência de Compra e Aspectos Emocionais relacionados à Compra. Esses resultados revelaram a insatisfação desses consumidores com diversos aspectos da experiência de consumo, principalmente no que se refere à dificuldade de achar roupas, $\mathrm{o}$ alto preço, a falta de identificação e os impactos na autoestima. Este estudo contribuiu para um maior entendimento do contexto de consumo e do comportamento do consumidor neste segmento. Também traz importantes considerações para a tomada de decisão de marketing no varejo de moda.

Palavras-chave: Experiência de Consumo. Plus Size. Varejo de Moda.

Natasha Migon Duarte natashamduarte@hotmail.com Graduada em Administração pela Pontifícia Universidade Católica do Rio Grande do Sul. Porto Alegre - RS - BR.

Elvisnei Camargo Conceição elvisneicamargo@gmail.com Doutorando em Gestão de Empresas pela Universidade de Coimbra, UC, Portugal. Professor da Pontificia Universidade Católica do Rio Grande do Sul. Porto Alegre - RS - BR.

\begin{abstract}
Considering the increase in the Brazilian overweight population in contrast with a plus size fashion market still in development, this article investigates the concept of clothing consumption experience from the perspective of plus size consumers. This is a qualitative research, carried out through 10 in-depth interviews with consumers in this segment. The results obtained through a content analysis identified three thematic categories: Product Experience, Purchase Experience and Emotional Aspects related to
\end{abstract}


Purchase. These results revealed the dissatisfaction of these consumers with several aspects of the consumption experience, mainly regarding the difficulty of finding clothes, the high price, the lack of identification, and the impacts on self-esteem. This study contributed to a greater understanding of the consumption context and consumer behavior in this segment. It also brings important considerations for market decision making in fashion retailing.

Keywords: Consumption Experience. Plus Size. Fashion Retailing.

\section{INTRODUÇÃO}

Em diversas épocas da história da humanidade, os corpos que possuíam mais gordura eram sinônimos de riqueza, beleza e status. Até os dias de hoje, em alguns países, onde a fome e a pobreza prevalecem, a obesidade ainda é vista sob essa perspectiva. Entretanto, nas últimas décadas, tem-se observado uma mudança em relação aos padrões de beleza que passaram a venerar corpos magros e musculosos, despertando uma pressão social para atingir essa "forma ideal" e fazendo que muitas pessoas busquem por dietas milagrosas, exercícios físicos e cirurgias plásticas (SOUSA JÚNIOR, 2018). Em concordância com esse autor, Marcelja (2015) enfatiza que o padrão de beleza da sociedade contemporânea é representado por um corpo saudável, jovem, magro e atlético, e ainda afirma que a obesidade é vista por muitos como descuido do próprio corpo. De fato, os termos "saudável" e "magro" são trazidos juntos como complementares, fazendo que exista uma desvalorização do corpo gordo (BETTI, 2014).

Paradoxalmente a isso, no cenário atual, a obesidade é uma doença crônica preocupante que, segundo dados da Organização Mundial da Saúde - OMS (DCI, 2018), afeta um em cada oito adultos no mundo. De acordo com a OMS, a projeção é de que, em 2025, cerca de 2,3 bilhões de indivíduos estarão acima do peso, sendo 700 milhões com obesidade. No Brasil, segundo dados da Vigilância de Fatores de Risco e Proteção para Doenças Crônicas por Inquérito Telefônico - Vigitel (BRASIL, 2018) divulgados pelo Ministério da Saúde, mais da metade $(53,8 \%)$ da população está com excesso de peso e, aproximadamente, $20 \%$ desta é obesa. Tal pesquisa ainda afirma que, em 10 anos, a obesidade cresceu $60 \%$ no país.

Com o aumento significativo de pessoas acima do peso e, considerando que estas são potenciais consumidoras, espera-se que o mercado se adapte a essa nova realidade, principalmente o varejo de moda. Em virtude disso, a confecção de roupas plus size (do inglês, "tamanho maior") surgiu para atender a essa demanda crescente. Segundo a Associação Brasileira de Plus Size - ABPS (2018), o mercado de plus size cresceu 7,9\% e teve uma arrecadação de 7,1 bilhões no ano de 2017. Além disso, segundo Matias (2017), os estudos realizados pela IEMI - Inteligência de Mercado (2016) mostraram que $30,4 \%$ dos fabricantes de moda feminina e $19,8 \%$ de moda masculina já incluem roupas plus size em sua produção.

Apesar de esse segmento ter ganho um destaque maior nos últimos anos e estar evoluindo (SOUSA JÚNIOR; MELO, 2019; BETTI, 2014), o mercado de moda ainda não é voltado para os consumidores acima do peso, os quais possuem necessidades particulares como modelagem específica (SERRÃO et al., 2016). Isso pode ser observado nas dificuldades enfrentadas por esses consumidores em encontrar roupas com tamanhos maiores em lojas comuns (BETTI, 2014), pois geralmente essas lojas não têm peças plus size ou possuem pouca diversidade de modelos (SOUSA JÚNIOR; MELO, 2019; BETTI, 2014).

Nesse cenário, surgem as lojas especializadas em moda plus size, justamente para atender e agradar a esse nicho, tão específico, de consumidores. Destaca-se como exemplo a marca Ashua, do Grupo Renner, que conta com lojas exclusivas para as mulheres que vestem do tamanho 46 ao 54. A loja possui uma área de vendas ampla com facilidade de locomoção assim como provadores grandes, acessíveis e iluminados, além de oferecer um serviço de 
venda móvel para evitar filas e fornecer maior comodidade. Tais características proporcionam uma melhor experiência de compra aos clientes plus size quando comparados ao varejo tradicional. Dado que alguns aspectos relacionados ao excesso de peso podem trazer obstáculos à compra (ROMEO; LEE, 2015), torna-se importante oferecer uma experiência prazerosa para esses clientes, objetivando atender às suas necessidades durante toda a experiência de consumo. Portanto, diante do aqui exposto, tem-se como questão central de pesquisa: Como os consumidores plus size percebem suas experiências de consumo no varejo de moda? Em virtude dessa problemática de pesquisa, este estudo tem como objetivo analisar a experiência de consumo de pessoas plus size no varejo de moda. Para subsidiar o alcance do objetivo geral, fixaram-se alguns objetivos específicos: a) identificar os atributos mais valorizados por consumidores plus size; b) definir a percepção que os consumidores plus size têm sobre o varejo de moda; c) identificar os aspectos valorizados no momento de compra; d) descrever as experiências de compra e seus resultados e, por fim e) verificar o que torna uma experiência boa ou ruim.

Encontra-se justificativa para este estudo a crescente demanda e o potencial de crescimento do varejo de moda plus size que, aparentemente, ainda não atende satisfatoriamente os consumidores. É importante e relevante o estudo a respeito da percepção desses consumidores, pois ainda são escassos os estudos na área de negócios a investigar o comportamento desse público. Além disso, destaca-se a importância de investigar todos os estágios da experiência de consumo.

Além dessa introdução, este artigo apresenta uma revisão da literatura (seção 2), trazendo sínteses sobre experiência de consumo, varejo de moda e consumidor plus size. Seguida do método de pesquisa adotada (seção 3), a análise e discussão dos resultados (seção 4) e, por último, as considerações finais (seção 5).

\section{REVISÃO DA LITERATURA}

Este trabalho possui a revisão da literatura dividida em Experiência de Consumo (subseção 2.1), Varejo de Moda (subseção 2.2) e Consumidor Plus Size (subseção 2.3).

\subsection{EXPERIÊNCIA DE CONSUMO}

O Marketing Science Institute (2014, 2016, 2018) identifica que compreender a experiência de consumo é um dos maiores objetivos dos estudos de marketing na atualidade, provavelmente devido à complexidade dos pontos de contato entre o consumidor e a empresa e a crença de que experiências positivas podem contribuir para a lealdade do cliente (LEMON; VERHOEF, 2016). De fato, pesquisadores desse conceito afirmam que a experiência do consumidor é um papel importante para o sucesso empresarial (GENTILE; SPILLER; NOCI, 2007).

Na década de 1950, Abbott (1955) salientou que, no momento de compra, as pessoas desejam experiências satisfatórias, e os produtos e serviços são apenas intermediários nesse processo. Nesse sentido, a funcionalidade e qualidade do produto são requisitos básicos na ótica do consumidor, pois este deseja uma experiência marcante (ACEVEDO; FAIRBANKS, 2018). Em continuidade, Machado (2018) ressalta a importância da experiência em vista do bem-estar sentido pelos consumidores após os momentos vividos. Na década de 1980, Hirschman e Holbrook (1982) foram os autores que introduziram a visão experiencial do consumo, reconhecendo a influência das emoções tanto na experiência, quanto no processo de decisão de compra. No entendimento deles, existe para o consumidor, além do valor utilitário (funcional) do produto, o valor hedônico da experiência que contempla a busca de sentimentos, diversão e fantasia no consumo. A partir desta nova visão, o consumidor foi considerado não apenas como um indivíduo racional ao consumir, mas também emocional (HÖPNER, 2017).

Alguns anos após os estudos de Abbott 
(1955) e Hirschman e Holbrook (1982), o termo experiência de consumo tornou-se mais relevante, especialmente para as organizações, quando Pine e Gilmore (1998) enfatizaram que criar experiências memoráveis aos clientes gera valor econômico para as empresas. Nos anos seguintes, observaram-se vários estudos sobre a experiência de consumo que levaram a algumas redefinições desse conceito. Schmitt (1999) identificou cinco tipos de experiências: sensoriais (sentir); afetivas (emocionar); físicas, estilo de vida e comportamento (agir); cognitivas (pensar) e de identidade social (relacionar). Gentile, Spiller e Noci, (2007) descrevem que a experiência de consumo é originada por uma série de interações entre o consumidor e a empresa, sendo a experiência exclusivamente pessoal e influenciada pelas expectativas do consumidor nos diversos pontos de contatos com a marca.

No contexto de varejo, Verhoef et al. (2009) definem que a experiência de consumo é um conceito holístico que envolve as respostas físicas, emocionais, cognitivas e sociais do consumidor durante todas as fases da experiência. Essa visão holista também é salientada por Lemon e Verhoef (2016) ao afirmarem que a experiência de consumo é multidimensional e engloba as diversas respostas comportamentais, sociais, cognitivas, emocionais e sensoriais do consumidor durante toda a jornada de consumo. Em concordância, Kranzbühler et al. (2018) reforçam que a experiência de consumo é formada quando o consumidor avalia, conforme seus sentidos, emoções e cognição, as interações (pontos de contato) com a empresa durante todo o processo de consumo. Conclui-se, então, que a experiência de consumo é interativa, emocional, racional e considera os diversos pontos de contato entre o indivíduo e a empresa ao longo de todas as fases da jornada do consumidor.

Nesse sentido, uma contribuição muito relevante é apresentada por Arnould, Price e Zinkhan (2002) que dividiram a experiência de consumo em quatro estágios: (1) experiência de pré-consumo, considerando a busca e o planejamento; (2) experiência de compra, envolvendo escolha, encontro com produto/serviço e pagamento; (3) núcleo da experiência de consumo, incluindo sensação e satisfação e, por último, (4) a experiência de consumo lembrada, assim como experiência de nostalgia, que contemplam experiências passadas. No entendimento de Lemon e Verhoef (2016), a experiência de consumo é composta por três fases: pré-compra, que engloba todas as interações do consumidor com a marca antes da compra; compra, definido por todas as interações com a marca e o ambiente durante o momento de compra; e, por fim, pós-compra relacionado à interação do consumidor com a marca, o ambiente e o produto ou serviço. Dado o exposto, torna-se importante assinalar que os conceitos 'experiência de consumo' e 'experiência de compra' não são sinônimos (SCUSSEL et al., 2018), pois a experiência de consumo envolve uma dimensão muito mais abrangente que apenas o momento de compra, considerando toda a jornada do consumidor (CARÙ; COVA, 2003; KRANZBÜHLER et al., 2018; LEMON; VERHOEF, 2016; MACHADO, 2018; SCUSSEL et al., 2018; VERHOEF et al., 2009).

Tendo em vista que a experiência de consumo é, de fato, uma trajetória, as empresas deveriam pensar na jornada de consumo sob a perspectiva dos clientes, verificando aspectos importantes em cada fase existente e descobrindo quais são os elementos que levam o consumidor a suspender a jornada (LEMON; VERHOEF, 2016). Além disso, as organizações devem considerar que a jornada do consumidor é influenciada por sensações e julgamentos de experiências passadas e fatores externos (HÖPNER, 2017; LEMON; VERHOEF, 2016), assim como compreender que alguns componentes da experiência estão sob o controle da empresa como o preço, o sortimento e o atendimento, porém certos fatores, como a influência de outros consumidores, estão além do controle dela (LEMON; VERHOEF, 2016).

No contexto da investigação apresentada neste artigo, dois aspectos do conceito experiência de consumo são essenciais: a interação e 
avaliação do consumidor. $\mathrm{O}$ primeiro considera as interações de consumidores plus size com a empresa, marca e o produto durante a jornada de consumo, e o segundo abrange as percepções (sensoriais, emocionais, cognitivas, físicas e sociais) deste público em relação às suas experiências no varejo de moda.

\subsection{VAREJO DE MODA}

Nas últimas duas décadas, o varejo sofreu transformações intensas na busca por modelos mais eficientes que atendam às necessidades do consumidor (MIOTTO; PARENTE, 2015). Com o surgimento de novos formatos comerciais, como lojas de conveniência, empresas globalizadas, franquias, shoppings centers e e-commerce (comércio virtual), as pessoas possuem diversas opções para efetivarem suas compras (PARENTE, 2000; ZORRILLA, 2002; MIOTTO; PARENTE, 2015). No que tange ao mercado de moda, formatos tradicionais antigos tendem a ser substituídos gradualmente por modelos mais modernos e eficazes (MIOTTO; PARENTE, 2015). Constantemente, os varejistas buscam, conforme esses autores, inovar para atrair os clientes e servi-los melhor. De acordo com Alvarez, Fávero e Luppe (2007), políticas de preço e localização do estabelecimento não são mais fatores críticos para o sucesso empresarial do varejista, tornando-se necessário buscar a diferenciação. Esses mesmos autores afirmam, ainda, que o cliente está mais complexo e deseja ver seus desejos atendidos. Com o intuito de atender às necessidades de um cliente mais informado, seletivo e exigente (ZORRILLA, 2002), muitas empresas têm visto as experiências proporcionadas aos consumidores como ferramenta estratégica para obter vantagem competitiva (SAMPAIO et al., 2009), dado que a experiência de consumo é um fator importante para a captação e fidelização de clientes (ZORRILLA, 2002; VERHOEF et al., 2009; LEMON; VERHOEF, 2016).

A experiência de consumo no varejo é vista por duas perspectivas: a do consumidor e a do varejista (VERHOEF et al., 2009). Do ponto de vista do consumidor, é necessário considerar que existem três tipos de clientes: essencialmente utilitários, essencialmente hedônicos e clientes com ambos os valores de compra (SOUSA et al., 2014). Os consumidores utilitários focam na compra, e o valor utilitário está relacionado ao sucesso da compra, podendo ser representado pela economia de tempo ou por ganhos econômicos (preço baixo ou desconto) (ALMEIDA et al., 2016). Os consumidores hedônicos, conforme esses autores, focam no consumo, e o valor hedônico está relacionado com as experiências proporcionadas, envolvendo aspectos emocionais e sensoriais. Em relação aos consumidores hedônicos, Sampaio et al. (2009) reforçam que a experiência de compra engloba aspectos intangíveis e emocionais, gerando valor na forma de gratificação pessoal. Machado (2018) concorda com Barros et al. (2018), quando afirma que o consumidor atual não deseja apenas comprar, mas anseia por sentir a experiência e felicidade na compra. Ainda convém observar que a perspectiva da experiência de consumo é individual e pode ser influenciada por experiências passadas e pela interação do consumidor com os vendedores e outros clientes (VERHOEF et al., 2009).

No que tange à perspectiva do varejista, Parente (2000) afirma que, na loja, os clientes formam opiniões e sensações, manifestam seu comportamento de compra e avaliam o varejista. Conforme Verhoef et al. (2009), existem aspectos da experiência de consumo que estão sob o controle do varejista, como atendimento, preço, sortimento e atmosfera da loja. Este último aspecto mencionado é um termo de marketing utilizado para descrever o esforço em construir um ambiente de compra que produza os efeitos desejados no consumidor, com a intenção de aumentar a probabilidade de compra (FARIAS, 2010; FARIAS; KOVACS; SILVA, 2008). Segundo Parente (2000), a atmosfera é capaz de instigar o sentimento psicológico no consumidor que visita o ambiente de venda e pode ser vista como a per- 
sonalidade da loja. Segundos alguns autores, a atmosfera da loja afeta o comportamento do consumidor e pode aprimorar a experiência de compra (ZORRILLA, 2002; FARIAS; KOVACS; SILVA, 2008; FARIAS, 2010). A atmosfera da loja pode ser planejada e desenhada em torno de elementos funcionais para proporcionar uma percepção de melhor oferta (valor utilitário) e/ou em torno de aspectos que amplifiquem a experiência do consumo de forma mais completa e multidimensional (valor hedônico) (ALMEIDA et al., 2016). Nesse sentido, é importante ressaltar que, primeiramente, faz-se necessário atender às necessidades utilitárias do consumidor, pois, caso contrário, afetaria negativamente a percepção dos consumidores a respeito dos aspectos hedônicos (SAMPAIO et al., 2009).

Portanto, conforme visto, a ambientação da loja ganhou destaque, tornando-se um importante componente estratégico dos varejistas, afetando o comportamento do consumidor e influenciando a sua experiência e interação com a empresa. Assim, as decisões de design e layout tornam-se importantes para a apresentação do ponto de venda, externo (vitrine) e interno (ambiente) (PARENTE, 2000). Segundo o mesmo autor, a apresentação externa é responsável por instigar a curiosidade dos consumidores e, no ambiente interno, o cliente é envolvido por vários aspectos que irão formar suas ideias e impressões. Sutter, Plutarco e Parente (2012) reforçam que a atratividade do ambiente externo e interno tem o objetivo de conquistar a atenção do consumidor. Quanto ao ambiente interno, Sampaio et al. (2009) estudaram os fatores visuais de design e a sua influência no valor de compra do consumidor, chegando a quatro características que tiveram alto impacto: organização do ambiente, exposição das mercadorias, iluminação adequada e facilidade de localização de produtos. Quanto ao layout, Parente (2000) afirma que ele é determinado pela disposição dos equipamentos que expõem os produtos e pelo fluxo de circulação, influenciando diretamente a percepção do cliente sobre a loja. Portanto, o layout deve ser muito bem planejado para obter um uso eficiente do espaço ao mesmo tempo que proporciona um ambiente de venda agradável (PARENTE, 2000). Além dos fatores de design e layout, outro aspecto do ambiente de loja muito importante para os varejistas de moda são as técnicas de merchandising, que consistem em apresentar os produtos da forma mais comercial possível, alterando a exposição dos produtos periodicamente e utilizando a composição de peças (looks) em manequins junto com iluminação e plano de fundo para chamar a atenção dos consumidores (BARROS et al., 2018). Logo, a intenção do merchandising é utilizar técnicas para que os produtos se vendam praticamente sozinhos, melhorando a sua exposição no ponto de venda.

Outros aspectos sob o controle do varejista, de acordo com Verhoef et al. (2009), são o sortimento e o preço. Possuir uma boa variedade de marcas e disponibilidade imediata dos produtos é fundamental para atender às expectativas dos clientes e ser competitivo no mercado (ALMEIDA et al., 2016; SOUSA et al., 2014). De acordo com Parente (2000), o varejista enfrenta dois desafios ao definir o mix de produtos que a sua loja irá oferecer: a variedade excessiva e a variedade incompleta. Em relação ao preço, Parente (2000) ressalta que ele afeta diretamente a competitividade e o volume de vendas da empresa. De fato, esse fator está muito relacionado à comparação e avaliação das lojas nas quais o consumidor pode, eventualmente, realizar a sua compra (SOUSA et al., 2014). Entretanto, ainda que o preço tenha uma influência considerável na decisão do consumidor, outros elementos podem favorecer a experiência do consumidor para auferir mais valor de compra (ALMEIDA et al., 2016). Dado o exposto, percebe-se que o preço e o sortimento são aspectos importantes para atender os consumidores e que se mostram como grandes fatores competitivos para os varejistas.

Em relação à interação social da compra, a qualidade do atendimento prestado também se revela como um diferencial com- 
petitivo para as empresas (PARENTE, 2000). Ramos, Costa e Mazza (2012) afirmam que, quando o atendimento tem um bom desempenho, é possível desenvolver relações em longo prazo e manter a fidelização dos clientes. Tanto para consumidores utilitários, quanto para hedônicos, um bom atendimento é fundamental; embora, nas experiências de consumo hedônico, o atendimento seja visto como um meio de criar uma relação mais próxima com o consumidor, estreitando-a (ALMEIDA et al., 2016). Em concordância, Sousa et al. (2014) afirmam que o atendimento ultrapassa o valor utilitário e passa a constituir um aspecto importante da experiência de consumo.

Por outro lado, há um fator que afeta negativamente a experiência do consumidor, conhecido por crowding, que, segundo Brandão, Parente e Oliveira (2010), é a percepção do cliente a respeito da densidade humana, quando o ambiente está lotado de pessoas, e da densidade espacial, quando a loja possui uma quantidade excessiva de produtos em uma determinada área. Ambas as densidades restringem e limitam as atividades do consumidor, afirmam os autores. Dreger (2016) destaca que, quando o cliente percebe o ambiente cheio, ele sente um enorme desconforto e desânimo, diminuindo sua intenção de compra e qualidade percebida da loja. Em situações de alta densidade humana dentro de uma loja, é possível que haja lentidão do serviço e má qualidade do atendimento, os quais abalam negativamente o nível de satisfação do cliente (BRANDÃO; PARENTE; OLIVEIRA, 2010).

Conclui-se, portanto, que a experiência de compra no varejo de moda tem influência de diversos aspectos como atmosfera da loja, design, layout, técnicas de merchandising, sortimento, preço, atendimento e crowding. Nesse sentido, os consumidores são mais que apenas receptores passivos, visto que eles interpretam e interagem constantemente com os elementos ambientais, visuais, sociais e espaciais que os cercam durante a experiência no varejo (PECORARO; UUSITALO, 2014). Além disso, ainda é importante mencionar que as experiências podem ser moldadas por valores utilitários e hedônicos que são percebidos pelos clientes e influenciam a decisão de compra. Por fim, convém mencionar que, na literatura, existem muitos estudos que buscam mensurar e analisar a experiência de compra dos consumidores (FARIAS; KOVACS; SILVA, 2008; RAMOS; COSTA; MAZZA, 2012; SAMPAIO et al., 2009; SOUSA et al., 2014); contudo, a análise de experiência de consumo ainda é pouco explorada.

\subsection{CONSUMIDOR PLUS SIZE}

O termo plus size, ou "tamanho maior" em português, originou-se nos Estados Unidos como uma nomenclatura mais sofisticada e moderna para designar a moda dirigida às mulheres acima do peso, substituindo outros nomes como "tamanho especial", "GG", "GGG" e similares (BETTI, 2014). Sousa Júnior e Melo (2018) comentam que plus size representa um termo mais simpático e menos agressivo aos consumidores, substituindo expressões que podem ser consideradas pejorativas como a palavra "gordo". Com uma visão mais humana, Silva (2018) afirma que o termo plus size não faz apologia à gordura em excesso, mas que busca encontrar um espaço na moda e no mundo social também. Para Sousa Júnior (2018), os termos "gordo" e "gorda" podem ter uma conotação negativa, por isso é preferível utilizar outros adjetivos mais apropriados para descrever o sobrepeso. De fato, o termo "gordo" pode ser usado na tentativa de ofender e humilhar alguém; entretanto, alguns indivíduos acima do peso utilizam essa palavra como autoafirmação, no sentido descritivo (BETTI, 2014).

$\mathrm{Na}$ literatura brasileira, não existe um consenso sobre qual numeração de roupa se inicia o plus size, pois, no país, há diferença nas modelagens dos tamanhos, principalmente os maiores (BETTI, 2014; SOUSA JÚNIOR, 2018). Devido à falta de padronização específica, a grade plus size inicia-se, dependendo do autor, a partir do tamanho 44 ou 46, que, 
geralmente, não são encontrados com facilidade na grande maioria das lojas de vestuário (BETTI, 2014; MARCELJA, 2015). Outro critério muito utilizado por alguns autores brasileiros, como Sousa Júnior (2018), Sousa Júnior e Melo (2018, 2019), é o Índice de Massa Corpórea (IMC). Conforme Sousa Júnior e Melo (2019, p. 2):

O peso ideal é definido com base no Índice de Massa Corpórea (IMC) que determina, a partir da divisão entre o peso do indivíduo por sua altura ao quadrado, que é ideal a faixa de valor que compreende entre 18,5 e 24,9. Assim, os indivíduos com valor igual ou superior a 25 são considerados gordos (apresentam-se dentro da faixa de sobrepeso ou nas faixas de obesidade).

De acordo com esse critério, existem indivíduos com sobrepeso (IMC de 25 a 29,9 $\mathrm{kg} / \mathrm{m}^{2}$ ), obesidade grau I (IMC de 30 a 34,9 $\mathrm{kg} / \mathrm{m}^{2}$ ), grau II (IMC de 35 a $29,9 \mathrm{~kg} / \mathrm{m}^{2}$ ) e grau III (IMC $>40 \mathrm{~kg} / \mathrm{m}^{2}$ ) (SOUSA JÚNIOR; MELO, 2018, 2019). Ainda de acordo com esses autores, quando se trata de alguns grupos específicos como idosos, grávidas, pessoas muito musculosas e atletas, o cálculo do IMC pode trazer resultados distorcidos e, portanto, não fidedignos.

O corpo gordo, diferente do magro, não é o ideal de beleza popularizado pela sociedade atual e sofre, muitas vezes, por não estar dentro de um padrão socialmente aceito (SILVA, 2018). É possível observar que existe um severo julgamento do corpo gordo, pois muitos acreditam que ele é fruto de descuido, falta de disciplina e preguiça, representando um sinal de desleixo com a própria forma (MARCELJA, 2015). Betti (2014) acrescenta que as pessoas obesas não são julgadas somente por sua estética, mas também pelo pensamento de que essas pessoas são relapsas e não zelam pela própria saúde. De fato, a sobrevalorização da magreza influencia o estigma associado a uma grande quantidade gordura, aumentando a re- provação do corpo gordo, uma vez que o obeso é identificado como preguiçoso e desleixado devido a sua forma física (MATTOS; LUZ, 2009). Portanto, o sobrepeso é estigmatizante, podendo afetar a vida do indivíduo de diversas maneiras, sendo uma delas a busca por peças de vestuário que pode tornar-se uma experiência desagradável (MARCELJA, 2015).

No comércio de vestuário, Scussel et al. (2018) explicam que as roupas plus size são expostas em uma "arara"1 mais afastada e que, geralmente, há uma identificação desses produtos, colaborando para que as pessoas obesas se sintam diferentes e estigmatizadas. Segundo os mesmos autores, outro fator que contribui para a estigmatização e desigualdade é a ausência de manequins plus size nas vitrines das lojas, impossibilitando a representação e a identificação de consumidores acima do peso. Segundo os achados da pesquisa de Betti (2014), os compradores plus size enfrentam uma enorme dificuldade para achar roupas que lhe agradem no varejo tradicional e, conforme a pesquisa de Sousa Júnior (2018), muitos acreditam que seria mais fácil emagrecer para serem socialmente aceitos e conseguirem comprar roupas. Uma forte percepção dos consumidores plus size é que eles não se percebem dentro da moda, pois eles não conseguem achar roupas que apresentem tendências de moda (SCUSSEL et al., 2018; SOUSA JÚNIOR; MELO, 2018, 2019) e, por causa disso, optam por adotar um estilo mais básico e confortável com roupas que sirvam (SOUSA JÚNIOR; MELO, 2018, 2019). Betti (2014, p. 62) ainda ressalta que: "Mais que o desejo por roupas "da moda", eles [consumidores plus size] precisam se vestir para o trabalho, para suas atividades cotidianas, para o lazer e outras ocasiões sociais." Outras duas dificuldades enfrentadas por esses consumidores estão relacionadas ao preço alto das roupas plus size em relação aos tamanhos menores e à falta de variedade das peças, com pouca variação de modelos e cores (SOUSA JÚNIOR,

1 Designação comercial dada a uma estrutura onde se expõem roupas. 
2018; SOUSA JÚNIOR; MELO, 2018, 2019). Portanto, conforme os aspectos mencionados, conclui-se que os consumidores plus size encontram dificuldade ao comprar itens de vestuário devido à ausência de moda, ao preço alto e à falta de variedade, podendo, muitas vezes, gerar um sentimento de descriminação e estigmatização. Em virtude desse cenário insatisfatório, tais consumidores têm realizado um movimento para as lojas virtuais, nas quais encontram maiores opções de roupas e preços mais acessíveis, além de uma maior comodidade sem a preocupação de conseguir achar roupas que realmente desejam e lhe sirvam bem em lojas físicas (SOUSA JÚNIOR, 2018; SOUSA JÚNIOR; MELO, 2018).

Com o crescimento do plus size no Brasil, as agências de publicidade e os veículos de comunicação, como revistas, jornais e programas de televisão, notaram a dimensão desse movimento e passaram a colocar em pauta, cada vez mais regularmente, questões relacionadas a esse público como moda, desfiles e modelos plus size (BETTI, 2014). Nesse sentido, conforme a autora, surgem os blogs dedicados ao movimento plus size, representando um canal muito importante, no qual os indivíduos acima do peso, principalmente as mulheres, podem trocar informações e experiências, interagindo de forma mais aberta. Nesses blogs, há dicas sobre como se vestir, informações sobre lojas especializadas em moda plus size físicas e on-line, discursos de autoestima, além de informações sobre beleza e saúde (BETTI, 2014). Tavares e Castro (2018) ressaltam que os blogs destinados ao plus size servem como um ambiente virtual, no qual as pessoas com sobrepeso possam se aceitar e desenvolver a autoestima, associando o corpo gordo a um corpo que também pode ser atraente, bem cuidado e saudável. Assim, com a popularização do plus size nos meios de comunicação, surgiu o movimento Fat Pride (do inglês, "orgulho gordo"), o qual representa a aceitação e maior visibilidade do corpo gordo, considerando que as pessoas acima do peso também podem ser vaidosas, sensuais e orgulhosas das suas for- mas (SOUSA JÚNIOR, 2018). Além desse movimento, outro fator que contribuiu para o empoderamento desse público foram os desfiles dedicados exclusivamente para as modelos plus size, como o Fashion Weekend Plus-Size, criado em 2010, e o Desfile Mulheres Reais, criado em 2009 (BETTI, 2014).

Nos últimos anos, é notório que o varejo de moda plus size cresceu e ganhou destaque na mídia; entretanto, esse mercado pode avançar muito mais. Conforme Scussel et al. (2018), alguns consumidores plus size consideram as lojas especializadas como uma segregação discriminatória e prefeririam ir a lojas tradicionais do varejo para realizarem suas compras. Nesse sentido, os resultados da pesquisa de Sousa Júnior (2018) contribuem com esta colocação, pois os entrevistados concordam que o mercado de comércio de moda precisa adequar-se aos diversos tipos de corpos (magros ou gordos), priorizando a inclusão e a diversidade. Logo, observa-se um profundo desejo dos consumidores plus size de encontrar uma moda única, para todos.

\section{MÉTODO}

Este artigo apresenta uma pesquisa qualitativa que, de acordo com Flick (2009), é uma abordagem não padronizada que busca compreender os fenômenos sociais, assim como as perspectivas dos participantes, utilizando o texto como material empírico. Tendo em vista o presente objetivo de analisar a experiência de consumo de indivíduos plus size, o estudo é classificado quanto aos objetivos como exploratório e, quanto ao tempo, como de corte transversal, pois foi realizado em apenas um momento. A técnica de coleta escolhida foi a entrevista, pois resulta em um documento verbal formado pela fala moderadamente espontânea dos entrevistados que possuem liberdade para expor suas opiniões e emoções (BARDIN, 2016). Em virtude dessa técnica, o entrevistador possui um papel fundamental no sentido que deve conduzir a pesquisa com bastante cuidado 
para não interromper ou ainda influenciar o entrevistado, possuindo uma comunicação assertiva (BRITTO; FERES, 2011; FLICK, 2004). Como instrumento de coleta de dados, utilizou-se um roteiro de entrevistas baseado nas etapas da experiência de consumo propostas por Carù e Cova (2003) elaborados por Arnould, Price e Zinkhan (2002), assim como insights obtidos por meio de estudos realizados sobre o público plus size (SCUSSEL et al., 2018; SOUSA JÚNIOR; MELO, 2018, 2019).

Como plano de coleta de dados, foram entrevistadas apenas pessoas acima de 18 anos e, em virtude da carência de estudos que considerem os homens plus size na experiência de consumo no varejo de moda (SCUSSEL et al., 2018), considerou-se não apenas o público feminino, mas também o masculino. A amostra da pesquisa foi escolhida pelo método de amostragem não probabilística por conveniência, de acordo com os requisitos necessários (maioridade e plus size). Primeiramente, no mês de junho de 2019, foram realizadas três entrevistas como pré-teste para verificar a existência de possíveis problemas de compreensão ou interpretação das perguntas. A partir disso, foram realizados pequenos ajustes na construção das perguntas. Em Porto Alegre, no mês de julho de 2019, foram realizadas dez entrevistas via Skype com consumidores plus size brasileiros. No momento da entrevista, a pesquisadora, após uma explicação sobre o propósito do trabalho, confirmava a concordância dos entrevistados em participar da pesquisa e garantia a estes o anonimato das informações, conforme mencionado no Termo de Consentimento da Entrevista. Para garantir a padronização do processo de entrevista, utilizou-se como um instrumento de coleta de dados um roteiro de entrevista, semiestruturado, com perguntas abertas. As entrevistas foram gravadas, após a autorização dos entrevistados, e, posteriormente, foram transcritas em documento word pela própria pesquisadora. A duração média das entrevistas foi de 13 minutos. Para a aná- lise de dados, adotou-se a técnica de análise de conteúdo que, segundo Bardin (2016), é um método aplicado a textos e que visa conhecer essas mensagens para realizar deduções lógicas e procedimentais, sendo muito utilizada em pesquisas qualitativas. A técnica de análise de conteúdo escolhida foi a categorial-temática, que classifica as categorias e os temas mais frequentes identificados no conteúdo das entrevistas (BARDIN, 2016). Em relação à interpretação dos dados, foi utilizada a técnica de emparelhamento ou ainda pattern-matching, que visa associar os dados obtidos mediante a pesquisa com a revisão da literatura (vide seção 2) a fim de compará-los (LAVILLE; DIONNE, 1999).

\section{ANÁlise E DISCUSSÃo DOS RESULTADOS}

Esta seção apresenta os principais resultados identificados na análise das entrevistas. Inicialmente, foi elaborada a Descrição dos Entrevistados (subseção 4.1) e, posteriormente, foram classificadas e apresentadas três categorias temáticas (subseção 4.2, 4.3 e 4.4).

\subsection{DESCRIÇÃO DOS ENTREVISTADOS}

Conforme relatado no método, foram entrevistadas dez pessoas plus size brasileiras, que apresentavam idade entre 21 e 53 anos. A pesquisadora buscou atingir um equilíbrio ao escolher o gênero dos entrevistados, resultando em seis mulheres e quatro homens. Isso permitiu obter opiniões femininas e masculinas sobre a experiência de consumo. O perfil dos entrevistados e a duração da entrevista estão relacionados no quadro 1 , abaixo. 
Quadro 1 - Perfil dos Entrevistados e Duração da Entrevista

\begin{tabular}{|c|c|c|c|c|c|}
\hline Entrevistado & Sexo & Idade & Profissão & Faixa de Renda Familiar Mensal & Tempo de Entrevista \\
\hline 1 & Feminino & 21 anos & Estudante & $\mathrm{R} \$ 10.000$ a $\mathrm{R} \$ 20.000$ & $18 \mathrm{~min}$ e $5 \mathrm{~s}$ \\
\hline 2 & Feminino & 27 anos & Analista de CRM & $\mathrm{R} \$ 2.000$ a $R \$ 4.000$ & 11 min e $31 \mathrm{~s}$ \\
\hline 3 & Feminino & 23 anos & Assistente Administrativo & $\mathrm{R} \$ 4.000$ a $\mathrm{R} \$ 10.000,00$ & 8 min e $49 \mathrm{~s}$ \\
\hline 4 & Feminino & 22 anos & Estudante & $\mathrm{R} \$ 4.000$ a $R \$ 10.000,00$ & 15 min e $9 \mathrm{~s}$ \\
\hline 5 & Feminino & 28 anos & Dona de Casa & Até $\mathrm{R} \$ 2.000,00$ & 12 min e $54 \mathrm{~s}$ \\
\hline 6 & Masculino & 35 anos & Comprador & $\mathrm{R} \$ 2.000$ a $R \$ 4.000$ & 8 min e $6 \mathrm{~s}$ \\
\hline 7 & Masculino & 31 anos & Coordenador de TI & $\mathrm{R} \$ 10.000$ a $R \$ 20.000$ & 13 min e $11 \mathrm{~s}$ \\
\hline 8 & Feminino & 41 anos & Professora Universitária & $\mathrm{R} \$ 10.000$ a $R \$ 20.000$ & 21 mine $22 \mathrm{~s}$ \\
\hline 9 & Masculino & 28 anos & Segurança & $\mathrm{R} \$ 2.000$ a $R \$ 4.000$ & 07 min e $56 \mathrm{~s}$ \\
\hline 10 & Masculino & 53 anos & Profissional de Marketing & $\mathrm{R} \$ 20.000,00$ ou mais & 18 min e $16 \mathrm{~s}$ \\
\hline
\end{tabular}

Fonte: elaborado pelos autores (2019).

Para auxiliar na análise do conteúdo das entrevistas transcritas, utilizou-se o software Atlas.ti. Após diversas leituras e interpretações desse material, foram classificadas três categorias distintas: Experiência com o Produto, Experiência de Compra e Aspectos Emocionais relacionados à Compra. Estas foram identificadas de acordo com a regularidade que apresentaram na análise qualitativa, considerando as dez entrevistas realizadas. Posteriormente, foram determinados os temas relacionados a cada categoria identificada conforme a frequência nos relatos. A seguir, cada categoria e temas ${ }^{2}$ concernentes são apresentados e exemplificados.

\subsection{EXPERIÊNCIA COM O PRODUTO}

A primeira categoria trata da interação do consumidor com as roupas plus size, resultando em percepções e opiniões sobre os atributos dessas peças. Os resultados indicaram cinco temas: baixa variedade, alto preço, ausência de padronização da modelagem, falta de tendências de moda e dificuldade de encontrar peças de roupas específicas.

No tocante ao sortimento, observou-se nas respostas que os entrevistados são unânimes em afirmar que há uma baixa variedade de vestuário plus size. Conforme a Entrevistada 1, "Não tem variedade pra gente. E

2 Os temas estão em ordem decrescente de frequência em que surgiram nas falas dos entrevistados. esse é um problema bem recorrente: às vezes tu quer uma cor de uma blusa ou modelo, mas não tem em tamanho maior. Aí, não tem o que fazer [...]". Compartilhando da mesma opinião, o Entrevistado 10 reflete e, posteriormente, esclarece sua percepção sobre o tema:

$\mathrm{Eu}$ percebo que existe muito mais variedade de modelos para tamanhos menores, porque quando eu peço um determinado modelo que gostei, na maioria das vezes, eu escuto que aquele modelo não tem em tamanho maior. Acho que quando a pessoa é plus size, ela tem uma limitação muito grande de sortimento, ou seja, a disponibilidade da loja para atender (ENTREVISTADO 10).

Conforme a literatura consultada, a variedade constitui um elemento essencial e estratégico para atender às necessidades e às expectativas dos clientes de maneira eficaz (SOUSA et al., 2014); entretanto, observa-se nos relatos a insatisfação com a falta de variedade. Logo, em virtude da pouca oferta de roupas plus size, a compra ocorre, geralmente, pela disponibilidade desses itens e não por apreciação deles. Isso reflete o baixo poder de escolha que o público plus size possui ao comprar roupas. Além disso, notou-se que a maior parte dos entrevistados adotou um estilo básico por falta de opção de vestuário em numerações maiores. Essa característica pode ser notada na fala da Entre- 
vistada 4: "Eu acabo tendo um estilo mais básico, porque não tem o que comprar. Eu acabo comprando o que é mais confortável...", assim como no relato da Entrevistada 1 "Meu estilo é por consequência da falta de opção no mercado, porque eu geralmente não encontro. Tipo... eu criei um estilo que eu fui me encontrando $e$ que era mais acessivel e fácil de encontrar". Esse achado é coerente com a pesquisa de Sousa Júnior e Melo (2018), na qual os resultados indicam que os entrevistados se adaptaram a um estilo mais confortável e básico devido à falta de variedade.

O segundo tema mais citado refere-se ao alto preço das roupas plus size, especialmente quando comparado à média de preço de roupas menores. Isso pode ser observado no comentário da Entrevistada 5 "É tipo muito mais caro as roupas plus size. Às vezes, é o dobro ou triplo do valor de roupas normais. Parece que são [roupas] especiais mesmo, sabe?". Segundo os resultados, as pessoas que usam tamanhos maiores de vestuário precisam ter mais poder aquisitivo para efetuarem suas compras de roupas. Neste sentido, a Entrevistada 3 afirma que "O preço é muito mais alto! As roupas plus size são caras, tu precisa ser rico para conseguir comprar! É um absurdo!”. Em vista dos relatos expostos, nota-se que as roupas plus size não representam uma moda acessível, concordando os resultados obtidos na pesquisa de Sousa Júnior e Melo (2019). Além disso, ainda convém ressaltar que, devido ao alto preço, o estilo dos entrevistados não é conforme eles gostariam. Isso pode ser observado nas palavras da Entrevistada 1: "Se tu é gordo e pobre é muito difícil ter o estilo que tu gostaria de ter, porque tu usa o mais básico, porque é por mais em conta" e da Entrevistada 2: "Eu tornei o meu estilo mais normal e basicão, porque eu não tenho como pagar tão caro em todas as peças de roupas".

$\mathrm{O}$ terceiro tema refere-se à ausência da padronização da modelagem, que gera uma grande frustação e decepção nos entrevistados ao experimentar roupas. Para eles, não existem padrões de modelagem em roupas plus size nas lojas. Conforme relata o Entrevistado 10 "Per- cebo [a diferença na modelagem] na mesma loja e não só em lojas diferentes. Muitas vezes, numa mesma loja eu entro no tamanho 54, peço outro modelo da roupa, mas não serve". Similarmente, a Entrevistada 1 comenta a respeito desse tema, contando sobre suas experiências e expressando seu descontentamento:

Tem lojas que eu chego a usar o tamanho $G G$ e peças que dependendo do tecido eu consigo usar $G$, mas tem lojas que até o GGG não serve. Então é muito discrepante, então eu acho que deveriam tentar fazer um padrão entre as lojas e ser um padrão que fosse real! E não um $G$ que não cabe nem um em $M$ direito. Isso é uma coisa que precisam ver (ENTREVISTADA 1).

Além disso, os entrevistados revelam que esse problema não ocorre somente nas mesmas lojas, mas também com a mesma marca de vestuário. Neste sentido, a Entrevistada 8 comenta que "Tem muito problema de modelagem sim! E o que me incomoda mais é que em uma mesma loja, uma mesma marca,o tamanho não bater! Isso me deixa possessa!". Tais resultados se assemelham com os achados de pesquisas anteriores (BETTI, 2014; SOUSA JÚNIOR, 2018), os quais revelam que as roupas plus size não seguem um padrão de medidas. E, devido à baixa incompatibilidade da modelagem, é necessário que o cliente experimente diferentes tamanhos para cada modelo de roupa, despendendo muito tempo e esforço. Deste modo, a experiência de consumo torna-se exaustiva e frustrante.

O quarto tema diz respeito à falta de tendências de moda nas peças destinadas aos tamanhos maiores. Essa carência não representa uma novidade para o público plus size, pois, de acordo com os entrevistados, eles não esperam encontrar roupas "da moda" em seus tamanhos. A Entrevistada 4 comenta que "Geralmente quando lança uma tendência nova, a gente não acha no tamanho grande. Então eu nem espero muito por isso", concordando com a fala da En- 
trevistada 6 "É muito difícil encontrar tendências de moda em roupas maiores, sabe? Acho que as tendências não são pra esse público...”. O Entrevistado 7 ainda expressa que "O gordo não consegue ficar na moda, sabe? Tem roupa que não existe no tamanho maior". Segundo a concepção de grande parte dos entrevistados, as roupas de confecção maior são mais tradicionais e pouco joviais, sendo caracterizadas regularmente como "cafonas", "maduras" e "roupas para pessoas mais velhas".

No que tange à dificuldade de encontrar roupas específicas, alguns entrevistados relataram que as opções de calça jeans são limitadas e que a modelagem, muitas vezes, representa um obstáculo. A Entrevistada 4 revela que "Calça é uma coisa muito difícil de achar, realmente. Eu nunca acho! Elas ficam apertadas nas coxas e sobrando um pouco na canela, daí fica muito estranho e eu acabo não comprando". Outro item fortemente ressaltado pelas mulheres desta pesquisa foram as roupas íntimas, especialmente sutiãs. A Entrevistada 8 relata que "Tenho muito problema em conseguir sutiã, porque eu tenho as costas largas, mas seios médios. E como eles aumentam bojo e costas proporcionalmente, o sutiã não cabe. Sutiã é o meu maior desafio, é terrivel'. Tais relatos evidenciam a falta de adequação deste mercado às necessidades do público plus size, concordando com os resultados de Scussel et al. (2018).

\subsection{EXPERIÊNCIA DE COMPRA}

A segunda categoria considera os elementos e os acontecimentos presentes na interação entre o consumidor e a conjuntura do ambiente de compra. Os resultados indicaram cinco temas: dificuldade de encontrar roupas, preferência pelas mesmas lojas, baixa frequência de compra, exposição das roupas e atendimento.

Nesta categoria, o tema destaque corresponde à dificuldade de encontrar roupas plus size, especialmente em lojas de departamentos. Contrário dos resultados de Scussel et al. (2018), os entrevistados não consideram essas lojas uma opção favorável à experiência de compra, assim como lojas de shoppings em geral. O Entrevistado 10 conta que "Quando eu vou em uma loja de departamento, eu já entro sabendo que a maioria das coisas que eu vou escolher, não vai ter o meu tamanho. Então, eu já procuro pelos tamanhos maiores, porque sei que são poucos". Colaborando com esse comentário, a Entrevistada 8 revela que "Ia em várias lojas e não achava nada! 90\% das lojas só tinham P, M ou G! Além de G, é difícil. Por isso nem compro mais em shoppings!". Portanto, mesmo que exista um aumento da população brasileira acima do peso (DCI, 2018), o mercado de moda ainda não abastece, de forma eficaz, a demanda por roupas plus size nos grandes centros de venda.

Por consequência desse contexto, os entrevistados afirmam que possuem preferência pelas mesmas lojas ao fazerem suas compras de vestuário, pois, assim, eles têm certeza de que encontrarão algumas peças de roupas, evitando frustações e poupando tempo. Isso pode ser observado na seguinte fala do Entrevistado 7 "Hoje, eu já sei os caminhos, então eu vou nas lojas que eu já conheço e sei que vai ter alguma roupa. Daí, não perco tempo procurando" e no comentário do Entrevistado 9 "Eu vou exatamente em apenas 2 lojas que eu sei que vai ter roupa pra mim. Melhor do que ir nas lojas e não achar nada, né? Isso é complicado, sabe...".

Essas circunstâncias levam os entrevistados a apresentarem uma baixa frequência de compra de roupas, pois essa atividade, muitas vezes, não é prazerosa para esse público. Isso pode ser notado no relato do Entrevistado 6 "Realmente, não são experiências legais, então é uma coisa que eu evito fazer, porque é desagradável'. Além disso, percebe-se que, de acordo com os resultados, as compras de vestuário plus size são motivadas principalmente pela necessidade, e esses consumidores são mais pragmáticos. Neste sentido, o Entrevistado 10 comenta que "O meu objetivo é endereçar uma necessidade, eu não tenho objetivo de lazer, entretenimento. Eu tenho uma necessidade e preciso resolver no tempo que eu tenho". Tais 
achados concordam com a pesquisa de Scussel et al. (2018) e refletem sobre uma possível falta de estímulos hedônicos destinados às pessoas plus size por parte do mercado de moda.

No que tange à exposição das roupas, os entrevistados relatam que dificilmente elas estão bem expostas dentro das lojas e que, normalmente, estão "escondidas". O Entrevistado 9 explica que "As roupas não são bem expostas dentro das lojas, porque existe um cantinho especial que eles colocam né, 'Roupas Especiais'. Dai é uma arara pequena que tu precisa sair procurando, geralmente fica num canto da loja, lá no fundo". Segundo a Entrevistada 4 "[...]tu tem que garimpar e procurar, se não, não acha". Percebe-se que, dessa maneira, a experiência de compra torna-se árdua e desagradável, pois os consumidores plus size precisam vasculhar a loja na esperança de encontrar a "seção especial", diferentemente das pessoas que utilizam tamanhos padrões. Essa distinção contribui para que este público se sinta excluído e até estigmatizado muitas vezes (ZANETTE; LOURENÇO; BRITO, 2013).

Referente ao atendimento, alguns entrevistados revelam que os vendedores apresentam falta de vontade e interesse ao atendê-los. Isto, pois, usualmente, os atendentes não mostram as opções de peças disponíveis nem os acompanham dentro da loja. Além disso, relatam que há um preconceito acerca do uso de tamanho plus size. A Entrevistada 5 comenta que:

Eles não sentem muita vontade em te atender, ir lá e te mostrar as roupas... Isso até porque não tem variedade, tipo... Se entrou eu e depois entrou outra pessoa mais magrinha na loja, o vendedor tem muito mais chance de vender roupa pra magrinha do que pra mim. Então, eles vão querer atender a outra pessoa, não eu (ENTREVISTADA 5).

Conforme a literatura, um bom atendimento é capaz de formar laços significativos entre o consumidor e a marca, nutrindo a fidelização dos clientes (RAMOS; COSTA; MA-
ZZA, 2012). Entretanto, em virtude da falta de variedade de peças em tamanhos maiores, é possível que os vendedores não se sintam motivados ao atender esse nicho. Mas, pode-se afirmar que esta é uma interpretação feita por meio das percepções dos entrevistados, não sendo possível declarar-se verdadeira à luz da intenção dos vendedores. Tendo em vista que o atendimento é um aspecto fundamental da experiência de compra, torna-se necessário o desenvolvimento de um atendimento mais personalizado para o público plus size.

\subsection{ASPECTOS EMOCIONAIS RELACIONADOS A COMPRA}

A terceira categoria aborda o impacto emocional gerado pelas situações vivenciadas com a compra de roupas plus size, que contemplam a experiência de consumo como um todo. Os resultados indicaram três temas: sentimentos negativos atrelados à compra de roupas, falta de identificação e impacto na autoestima.

Embora o ato de comprar roupas esteja relacionado a "prazer" e "lazer", para muitas pessoas, os entrevistados desta pesquisa concordam que, na maioria das vezes, essa atividade não resulta em boas experiências para os indivíduos plus size. Em virtude disso, eles apresentam sentimentos negativos atrelados à compra de roupas conforme a Entrevistada 4 comenta "Eu fico muito triste, brava, porque é muito constrangedor entrar numa loja e não conseguir comprar nada! E não porque tu não gostou de nada, mas porque nada serviu”. Ao dizer que "Durante muito tempo, eu tive aversão ao comprar roupas, eu achava traumatizante e não sabia o que fazer", o Entrevistado 7 revela frustação e desprazer ao refletir sobre suas experiências de compra de roupas. Nesse sentido, a Entrevistada 2 explica que:

Tem que estar num mood legal quando tu é gordo e precisa comprar roupa, porque não é uma experiência tão agradável e legal, sabe... Então, sempre fico com as expectativas controladas para não sofrer depois, ficando 
muito chateada ou brava! (ENTREVISTADA 2).

Além disso, percebe-se que os entrevistados se sentem ignorados no que tange ao mercado da moda, especialmente quando comparado com as experiências de consumo de pessoas que não utilizam tamanhos plus size. Isso pode ser percebido na resposta dada pela Entrevistada 3 "É bem mais fácil e divertido pra pessoa que tem o tamanho padrão, não tão grande. Elas conseguem achar roupas com maior qualidade e bom preço, com certeza. E já o plus size tem que entender que o processo de compra é mais difícil, infelizmente". Esses achados corroboram as pesquisas de Betti (2014) e de Scussel et al. (2018), ao apontarem que, os indivíduos plus size podem vir a ter sentimentos desagradáveis e insatisfatórios ao comprarem roupas devido às dificuldades existentes em utilizar uma numeração maior. O Entrevistado 7 afirma que "O gordo não é visto pela sociedade quando se trata de roupa! Não temos poder de escolha... O mercado precisa entender que essas pessoas [gordas] existem, sabe?". De acordo com as falas dos entrevistados, é evidente o desejo por um mercado de moda mais inclusivo para o público plus size, ou seja, uma oferta de vestuário com maior sortimento, mais variedade e preço acessível.

No tocante à falta de identificação, os entrevistados são unânimes em afirmar que existe pouca informação de moda plus size disponível nos veículos de comunicação, especialmente quando se trata de propagandas de televisão. Em virtude disso, eles preferem buscar por este conteúdo na internet, utilizando redes sociais como Instagram. Desta forma, percebe-se que esse público, além de ser carente de opções de vestuário, também é desprovido de informações de moda. Ademais, grande parte dos entrevistados comentam sobre a exposição limitada e até ausência de manequins plus size nas vitrines das lojas, principalmente quando se trata da figura masculina. De acordo com o Entrevistado 7, "Não dá para saber se tem roupas plus size sem entrar na loja, porque não tem manequins que indiquem isso! Muito dificil ter [manequins plus size]". Considerando que a moda é um elemento da construção de identidade de um indivíduo (ZANETTE; LOURENÇO; BRITO, 2013), a falta de representação do corpo plus size por meio da exibição de manequins impossibilita a visualização das roupas e causa um sentimento de exclusão do mercado de moda. Posto isso, sugere-se que as empresas varejistas que trabalham com numerações maiores atentem-se para divulgação de propagandas e anúncios para esse público, bem como a exposição de manequins plus size. Assim, este consumidor poderá se sentir mais representado pelo mercado de moda, motivando-o a comprar roupas.

Para os entrevistados, algumas dificuldades acompanhadas da experiência de consumo de roupas plus size geram um impacto na autoestima, que, na maioria das vezes, não é positivo. Segundo eles, existe um grande sentimento de culpa e constrangimento por não encontrarem ou ainda não caberem nas roupas, que os leva a refletir sobre o seu peso e tamanho. O Entrevistado 10 esclarece que:

Porque você sente que se você tivesse um peso menor, você teria muitas mais opções e talvez pudesse pagar menos. Mas como você tem o peso que tem, você acaba tendo que se submeter ao preço e opções existentes. Isso dá uma sensação de que você poderia ter tido mais oportunidade, que, por ter um peso maior, você não tem (ENTREVISTADO 10).

Neste sentido, a valorização de corpos magros, nas últimas décadas (SOUSA JÚNIOR; MELO, 2019), e o estigma relacionado à gordura (MARCELJA, 2015) contribuem para que esse público se sinta desconsiderado. Em virtude disso, alguns entrevistados revelam que consideram fazer dietas e exercícios físicos para emagrecer a fim de evitarem frustações e se sentirem melhor ao fazer compras de roupas. Conforme Zanette, Lourenço e Brito (2013), a não aceitação do corpo e a escassez de pro- 
dutos plus size acabam fortalecendo o estigma relacionado à gordura e ao sentimento de não pertencimento ao mercado de moda. Considerando o que foi exposto nesta categoria, percebe-se que os aspectos emocionais relacionados à compra possuem uma influência significativa na experiência de consumo de roupas plus size, visto que impactam na percepção e motivação da compra.

\section{CONCLUSÃO}

Este artigo objetivou analisar a experiência de consumo de indivíduos plus size no varejo de moda, compreendendo a percepção sobre suas experiências, assim como os resultados delas. Desse modo, foram realizadas entrevistas semiestruturadas com dez consumidores deste segmento e, para análise, utilizou-se a técnica categorial temática. Os achados da pesquisa revelaram três categorias que possuíram maior relevância e frequência nos relatos dos entrevistados sobre suas experiências de consumo: Experiência com o Produto, Experiência de Compra e Aspectos Emocionais relacionados à Compra. Tais resultados reforçam que a experiência de consumo é um constructo multidimensional, que envolve as respostas físicas, emocionais, sociais e cognitivas do consumidor durante todas as fases do consumo, não se limitando apenas ao momento de compra do produto.

Nesta pesquisa, verificou-se que, quanto a categoria Experiência com o Produto, a baixa variedade de roupas plus size e alto preço das peças levam esses consumidores a adotarem um estilo mais básico, pois a compra ocorre conforme o sortimento e a acessibilidade. Nota-se, portanto, que a falta de poder de escolha é um aspecto presente nas experiências de consumo desse público. Além disso, a ausência de tendências de moda e de padronização da modelagem são fatores críticos que contribuem com o sentimento de exclusão do mercado. No que se refere à categoria Experiência de Compra, a extrema dificuldade em encontrar roupas plus size até em grandes centros de vendas causa frustração e desânimo, impactando negativamente a experiência de consumo. De fato, esse tema teve destaque e relevância nas entrevistas e inspirou a pergunta que dá título a este artigo. Em virtude dessa dificuldade, esses consumidores apresentam uma baixa frequência de compra e mantêm preferência pelas mesmas lojas, as quais possuem certeza de que conseguirão encontrar algumas peças. Destaca-se, ainda, a importância da interação dos vendedores e da exposição das roupas no momento de compra. Finalmente, os aspectos emocionais relacionados à compra revelam os impactos na autoestima em decorrência de não encontrar ou caber nas roupas, gerando sentimento de culpa e constrangimento. Além disso, a carência de conteúdo de moda direcionada ao público plus size, bem como a falta de manequins expostos nas lojas provocam uma sensação de não pertencimento ao mercado, pois esse público não se vê representado.

O mercado de moda plus size ganhou, de fato, mais atenção nas últimas décadas e vem crescendo no país. Mas, conforme os resultados, ainda é muito deficitário e não satisfaz, atualmente, esses consumidores. Nesse sentido, o varejo pode se tornar um instrumento que reflete a estigmatização desse público, pois a experiência de consumo não é um processo divertido, tampouco agradável. Portanto, faz-se necessário que as empresas e marcas que trabalham com a moda plus size analisem as principais reclamações e insatisfações destes consumidores a fim de corrigi-las e atendê-las. Assim, será possível proporcionar uma melhor experiência de consumo, motivando a compra de roupas, além de promover a visibilidade dos corpos gordos e até inserir socialmente este nicho.

No que tange às contribuições acadêmicas, este estudo aborda os consumidores plus size, um público que carece de estudos científicos, especialmente o gênero masculino. Além disso, espera-se colaborar com a distinção conceitual dos termos experiência de compra e experiência de consumo, dado que o último aborda todas as fases do consumo, incluindo a fase de compra. No que se refere às contribuições gerenciais, as empresas precisam observar, com 
mais atenção e interesse, o varejo de moda plus size no país, uma vez que a população brasileira acima do peso vem aumentando gradativamente e, mesmo assim, ela não é satisfatoriamente atendida pelo mercado de moda. Neste sentido, os achados desta pesquisa podem auxiliar as empresas que já atuam no segmento plus size a tomarem medidas corretivas a fim de aprimorar a experiência dos clientes plus size, associando o consumo da moda ao prazer. Ademais, os resultados podem contribuir para os profissionais do varejo de moda reconsiderarem sua estratégia e ações mercadológicas, tendo em vista o potencial desse nicho de consumidores desconsiderados, atualmente.

Embora o estudo aqui descrito apresente contribuições importantes para a análise da experiência de consumo de indivíduos plus size, ele apresenta algumas limitações. Inicialmente, planejou-se entrevistar dezesseis pessoas, sendo oito do gênero feminino e oito do masculino. Embora tenhamos obtido um número menor de entrevistados, esta pesquisa obteve um equilíbrio na participação de cada gênero dos entrevistados. Isto se deve a certa dificuldade em conseguir participantes plus size dispostos a falar sobre suas percepções a respeito do tema. $\mathrm{O}$ fato de termos uma concentração dos respondentes em uma determinada faixa de renda só não foi um limitador de impacto na pesquisa, por esta ser de natureza qualitativa. Portanto, não foi possível realizar uma análise de cada tema por faixa de renda familiar mensal, como era pretendido a princípio.

Quanto a recomendações para futuras pesquisas, sugere-se a busca por outras metodologias de pesquisa como experimentos para aprofundar a questão, ou ainda a utilização da técnica Focus Group que pode promover uma sensação de acolhimento e facilitar a conversa entre os participantes da pesquisa. Também se recomenda a investigação de consumidores plus size de baixa renda pois, considerando que este mercado pratica altos preços (comparativamente) e tem oferta limitada, questiona-se como se comportam esses consumidores que, tendo as mesmas necessidades, possuem poder de compra limitado. No mais, recomenda-se investigar as perspectivas dos varejistas quanto ao mercado de moda plus size e quais são as principais dificuldades. E, por fim, indica-se o estudo da experiência de consumo de roupas plus size no ambiente virtual, como em lojas on-line, entendendo as vantagens e desvantagens quando comparado com lojas físicas.

\section{REFERÊNCIAS}

ABBOTT, L. Quality and competition: an essay in economic theory. New York: Columbia University Press, 1955.

ABIESV. Mercado de Plus Size não conquistou nem $10 \%$ de seu potencial, segundo a ABPS. São Paulo: Portal do Varejo, 2018. Disponível em: http://portaldovarejo.com.br/mercado-plus-size-nao-conquistou-nem-10-de-seu-potencial-segundo-a-abps/. Acesso em: 2 abr. 2019.

ACEVEDO, C. R.; FAIRBANKS, V. S. L. Os efeitos do Marketing Sensorial sobre a experiência de compra do consumidor no ponto de venda. Revista Interdisciplinar de Marketing, Maringá, v. 8, n. 1, p. 51-67, jan./jun. 2018.

ALMEIDA, S. O. de et al. O contínuo experiencial do varejo: valor utilitário versus valor hedônico no mix de marketing varejista. Teoria e Prática em Administração, [S.l.], v. 6, n. 1, p. 97-128, 2016.

ALVAREZ, R. A. G.; FÁVERO, L. P. L.; LUPPE, M. R. Importância das variáveis intrínsecas e extrínsecas ao varejista como explicação de seu desempenho ao longo do tempo. FACEF Pesquisa, [S.l.], v. 10, n. 3, p. 309-316, 2007.

ARNOULD, E. J.; PRICE, L.; ZINKHAN, G. M. Consumers. New York: McGraw-Hill, 2002.

BARDIN, L. Análise de Conteúdo. São Paulo: Edições 70, 2016.

BARROS, L. B. L. et al. Visual Merchandising 
no varejo de moda e a experiência do consumidor: um estudo bibliométrico. Navus, Florianópolis, v. 8, n. 3, p 81-98, 2018.

BBC. Por que há uma explosão de obesidade no Brasil? G1, 19 abr. 2017. Disponível em: https:/g1.globo.com/ bemestar/noticia/por-que-ha-uma-explosao-de-obesidade-no-brasil.ghtml.Acessoem:2abr.2019.

BETTI, M. U. Beleza sem medidas? Corpo, gênero e consumo no mercado de moda plus-size. 2014. Dissertação (Mestre em Antropologia Social) - Faculdade de Filosofia, Letras e Ciências Humanas, Universidade de São Paulo, São Paulo, 2014.

BRANDÃO, M. M.; PARENTE, J.; OLIVEIRA, B. B. Percepção de Crowding no Varejo: uma investigação exploratória no mercado brasileiro. RAE, [S.l.], v. 9, n. 2, p. 1-24, 2010.

BRASIL. Ministério da Saúde. VIGITEL Brasil 2017: vigilância de fatores de risco e proteção para doenças crônicas por inquérito telefônico. Brasília, DF: Ministério da Saúde, 2018. Disponível em: https://bvsms.saude.gov.br/ bvs/publicacoes/vigitel_brasil_2017_vigilancia_fatores_riscos.pdf. Acesso em: 2 abr. 2019.

BRITTO, A. F. de; FERES, N. A utilização da técnica da entrevista em trabalhos científicos. Revista Evidência, Araxá, v. 7, n. 7, p. 237250, 2011.

CARÙ, A.; COVA, B. Revisiting consumption experience: a more humble but complete view of the concept. Marketing Theory, [S.l.], v. 3, n. 2, p 267-286, 2003.

DCI. Um em cada oito adultos no mundo é obeso, alerta OMS. Diário Comércio Indústria \& Serviços, São Paulo, 15 out. 2018. Disponível em: https://www.dci.com.br/impresso/um-em-cada-oito-adultos-no-mundo-e-obeso-alerta-oms-1.749271. Acesso em: 31 mar. 2019.
DREGER, A. R. O efeito da interação entre percepção de crowding e motivação de compra na qualidade percebida da loja e na intenção de compra do consumidor. 2016. Dissertação (Mestrado em Administração) Faculdade Administração, Contabilidade e Economia, PUCRS, Porto Alegre, 2016.

FARIAS, S. A. de; KOVACS, M. H.; SILVA, J. M. da. Comportamento do consumidor on-line: A perspectiva da teoria do fluxo. Revista Brasileira de Gestão de Negócios, São Paulo, v. 10, n. 26, p. 27-44, 2008.

FARIAS, S. A. de. Store atmospherics and experiential marketing: a conceptual framework and research propositions for an extraordinary customer experience. In: ENCONTRO DE MARKETING DA ANPAD, 4., 2010, Florianópolis. Anais [...]. Florianópolis: ANPAD, 2010. p. 1-13.

\section{FLICK, U. Desenho da Pesquisa Qua-} litativa. Porto Alegre: Artmed, 2009.

FLICK, U. Uma introdução à Pesquisa Qualitativa. 2. ed. Porto Alegre: Bookman, 2004.

GENTILE, C.; SPILLER, N.; NOCI, G. How to sustain the customer experience: an overview of experience components that co-create value with the customer. European Management Journal, [S.l.], v. 25, n. 5, p. 395-410, out. 2007.

HOLBROOK, M. B.; HIRSCHMAN, E. C. The experiential aspects of consumption: consumer fantasies, feelings and fun. Journal of Consumer Research, [S.l.], p. 132-140, set. 1982.

HÖPNER, A. Construção da experiência de consumo: um olhar para compreender o valor nas experiências. 2017. Tese (Doutorado em Administração) - Faculdade de Administração, Contabilidade e Economia, PUCRS, Porto Alegre, 2017. 
KRANZBÜHLER, A. M. et al. The multilevel nature of customer experience research: an integrative review and research agenda. International Journal of Management Reviews, [S.l.], v. 20, n. 2, p. 433-456, abr. 2018.

LAVILlE, C.; DIONNE, J. A construção do saber: manual de metodologia da pesquisa em ciências humanas. Porto Alegre: Artmed; Belo Horizonte: Editora UFMG, 1999.

LEMON, K. N.; VERHOEF, P. C. Understanding customer experience throughout the customer journey. Journal of Marketing, [S.l.], v. 80, n. 6, p. 69-96, nov. 2016.

MACHADO, M. A. D. Possuir ou experienciar? Entendendo as relações entre o materialismo e o experiencialismo ao longo do processo de consumo de uma experiência. 2018. Dissertação (Mestrado em Administração) - Escola de Negócios, PUCRS, Porto Alegre, 2018.

MARCELJA, K. G. A busca por uma identidade na moda plus size. In: CONGRESSO INTERNACIONAL DE COMUNICAÇÃO E CONSUMO, 5., 2015, São Paulo. Anais [...]. São Paulo: PUC-SP, 2015. Disponível em: http://anais-comunicon2015.espm.br/GTs/ GT2/6 GT02 Karen Grujicic Marcelja.pdf. Acesso em: 5 abr. 2019.

MATIAS, K. Apesar do preconceito, mulheres comemoram crescimento do mercado plus size; confira dicas. Folha de São Paulo, São Paulo, 30 jul. 2017. Disponível em: https://f5.folha. uol.com.br/estilo/2017/07/apesar-do-preconceito-mulheres-comemoram-crescimento-do-mercado-plus-size-confira-dicas.shtml. Acesso em: 2 abr. 2019.

MATTOS, R. da S.; LUZ, M. T. Sobrevivendo ao estigma da gordura: Um estudo socioantropológico sobre obesidade. Physis, Rio de Janeiro, v. 19, n. 2, p. 489-507, 2009.

MIOTTO, A. P.; PARENTE, J. G. Retail evolu- tion model in emerging markets: Apparel store formats in Brazil. International Journal of Retail and Distribution Management, [S.l.], v. 43, n. 3, p. 242-260, 2015.

MSI. 2014-2016 Research Priorities: Marketing Science Institute. Cambridge: [s.n.], 2014. Disponível em: https:/www.msi.org/uploads/ files/MSI_RP14-16.pdf. Acesso em: 14 abr. 2019.

MSI. 2016-2018 Research Priorities: Marketing Science Institute. Cambridge: [s.n.], 2016. Disponível em: https:/www.msi.org/uploads/ articles/MSI_RP16-18.pdf. Acesso em: 14 abr. 2019.

MSI. 2018-2020 Research Priorities: Marketing Science Institute. Cambridge: [s.n.], 2018. Disponível em: https:/www.msi.org/uploads/ articles/MSI_RP18-20.pdf. Acesso em: 14 abr. 2019.

NAVAJAS, L. Crescimento do mercado plus size começa a chamar a atenção das marcas. São Paulo: Portal do Varejo, 2017. Disponível em: https://portalnovarejo.com.br/2017/06/ crescimento-plus-size-atencao-das-marcas/. Acesso em: 2 abr. 2019.

PARENTE, J. Varejo no Brasil. São Paulo: Atlas, 2000.

PECORARO, M.; UUSITALO, O. Exploring the everyday retail experience: the discourses of Style and Design. Journal of Consumer Behaviour, [S.l.], v. 13, n. 6, p. 429-441, 2014.

PINE, J.; GILMORE, J. H. Welcome to the experience economy. Harvard Business Review, [S.l.], v. 76, p. 97-105, jun./ago. 1998.

RAMOS, R. R.; COSTA, F. J. da; MAZZA, I. Experiência do cliente no ponto de venda varejista: Desenvolvimento de uma escala de mensuração. Revista de Negócios, Blumenau, v. 17, n. 3, p. 20-36, 2012. 
ROMEO, L. D.; LEE, Y. A. Exploring apparel purchase issues with plus-size female teens. Journal of Fashion Marketing and Management, [S.l.], v. 19, n. 2, p. 120-135, 2015.

SAMPAIO, C. H. et al. Fatores visuais de design e sua influência nos valores de compra do consumidor. Revista de Administração de Empresas, São Paulo, v. 49, n. 4, p. 373-386, 2009.

SCHMITT, B. H. Experiential Marketing. New York: The Free Press, 1999.

SCUSSEL, F. B. C. et al. Muito além das curvas: a experiência de consumo das mulheres brasileiras plus size no varejo de moda. Alcance, Itajaí, v. 25, n. 1, p. 79-94, jan./abr. 2018.

SERRÃO, H. de C. N. et al. Avaliação ergonômica em lojas de roupas femininas plus size - estudo de caso em Caruaru e João Pessoa. In: ENCONTRO NACIONAL DE ERGONOMIA DO AMBIENTE CONSTRUÍDO, 6., 2016, São Paulo. Anais [...]. São Paulo: Blucher, 2016. p. 446-457. Disponível em: http://www. proceedings.blucher.com.br/article-details/avaliao-ergonmica-em-lojas-de-roupas-femininas-plus-size-estudo-de-caso-em-caruaru-e-joo-pessoa-22641. Acesso em: 5 abr. 2019.

SILVA, S. G. P. da. Produção de conteúdo e estratégias de comunicação de marcas: estudo de caso da digital influencer Ju Romano e a promoção de marcas plus size no instagram. 2018. Trabalho de Conclusão de Curso (Graduação em Comunicação Social) - Habilitação Publicidade e Propaganda, Unijuí, Ijuí, 2018.

SOUSA, F. G. P. et al. Comportamento de compra no pequeno varejo: consumo hedônico e utilitário. Revista Ciências Administrativas, Fortaleza, v. 20, n. 1, p. 285-312, 2014.

SOUSA JÚNIOR, J. H. de. Avaliação de consumidores gordos e magros em relação aos estímulos promocionais de moda plus size no varejo de vestuário. 2018. Disser- tação (Mestrado em Administração) - Centro de Ciências Sociais Aplicadas, Universidade Federal de Pernambuco, Recife, 2018.

SOUSA JÚNIOR, J. H. de; MELO, F. V. S. Moda além do "G": hábitos e preferências de consumo de vestuário de consumidores plus size. Revista da Universidade do Vale do Rio Verde, [S.l.], v. 17, n. 1, p. 1-9, jan./jul. 2019.

SOUSA JÚNIOR, J. H. de; MELO, F. V. S. Moda "Só para Maiores": Experiência de Consumo de Pessoas Obesas em Lojas Especializadas de Vestuário Plus Size. Revista Administração em Diálogo - RAD, São Paulo, v. 20, n. 3, p. 110-123, 2018.

SUTTER, M. B.; PLUTARCO, F.; PARENTE, J. Apresentação no Ponto de Vendas: um Estudo Exploratório no Varejo de Moda Popular. Análise, Porto Alegre, v. 23, n. 1, p. 5-18, 2012. TAVARES, H. O.; CASTRO, A. L. de. DISCURSO E PODER: a prescrição do controle corporal em blogs plus size. Revista De Ciências Sociais - Política \& Trabalho, [S.l.], v. 1, n. 47, p. 97-119, 2018.

VERHOEF, P. C. et al. Customer experience creation: determinants, dynamics and management strategies. Journal of Retailing, [S.l.], v. 85, n. 1, p. 31-41, 2009.

ZANETTE, M. C.; LOURENÇO, C. E.; BRITO E. P. Z. O peso do varejo, o peso no varejo e a identidade: Uma análise de consumidoras plus size. Revista de Administração de Empresas - ERA, São Paulo, v. 53, n. 6, p. 539550, 2013.

ZORRILLA, P. Nuevas tendencias en merchandising. Distribución y Consumo, [S.l.], n. 65, p. 13-20, 2002. 